\title{
Simulation Investigation of the Wind Load of Photovoltaic Panels
}

\author{
Ivaylo Stoyanov ${ }^{1 *}$, Teodor Iliev $^{2}$, and Grigor Mihaylov ${ }^{3}$ \\ ${ }^{1}$ University of Ruse, Department of Electrical Power Engineering, 7017 Ruse, Bulgaria \\ ${ }^{2}$ University of Ruse, Department of Telecommunications, 7017 Ruse, Bulgaria \\ ${ }^{3}$ University of Telecommunications and Posts, 1700 Sofia, Bulgaria
}

\begin{abstract}
In this article, a simulation and evaluation of the mechanical stress exerted by the wind on photovoltaic panels is performed. The stresses of the solar cells in a PV module are calculated using the finite element method, taking into account the wind pressure and the allowable mechanical stresses, according to the regulatory requirements. Seven different operating positions of the photovoltaic panel during its rotation from $0^{\circ}$ to $90^{\circ}$ are considered. In each of these positions, a distributed load for computer simulations is $1 \mathrm{kN} / \mathrm{m}^{2}$. It is clear from them that for all operating positions of the panel, the maximum stresses are obtained in its frame. These stresses in different cases vary around the value of $50 \mathrm{MPa}$ and are not dangerous for the structure.
\end{abstract}

\section{Introduction}

In order to achieve Bulgaria's national target for the share of energy from renewable sources in gross final energy consumption by 2030 , it is set that $30.33 \%$ of electricity should be produced from renewable energy sources (RES). This corresponds to an increasing trend of $0.55-1.24$ percentage points per year [1]. In this regard, a number of normative documents have been adopted, which support the faster and wider introduction of RES at national and regional level. On the other hand, it is known that in Bulgaria there are favorable conditions for electricity production using the photovoltaic system (PVS). Thus, a number of researchers have focused their efforts on improving their efficiency and improving the quality of electricity $[2,3,4,5]$. The introduction of these new technologies leads to a number of problems related to customer relationships, facility and utility management, surge protection, etc. $[6,7,8]$. However, one of the main problems is the mechanical sizing depending on the method of installation of PVS. For example, installation on the roofs of industrial buildings. But this increases the risk of leaks, and photovoltaic panels must withstand the high wind forces that act on them. There is also a wind load in the ground stationary and monitoring systems.

Damage to photovoltaic systems can be divided into electrical and mechanical damage [9]. In turn, mechanical damage occurs under the influence of climatic factors, defects in production and installation, and force majeure circumstances. The greatest influences of

\footnotetext{
* Corresponding author: stoyanov@uni-ruse.bg
} 
climatic factors have the load of wind and snow, temperature, hail and ultraviolet rays [10, $11,12]$. The analysis shows for the load from wind and snow that the structures on a sloping roof have with relatively the least load, and the structures on a flat roof - with the highest (due to the height of the building). Higher mechanical loads are observed in open terrains and in PVS with a larger area of the modules. Therefore, different methods are applied to study PVS using modeling and simulation [13, 14, 15, 16]. All of them are based on the data accumulated during the operation of PVS [17]. All this saves time and costs, and helps designers to find appropriate technical solutions in the construction and operation of PVS.

\section{Material and methods}

The main elements of the task for the manufacture of a metal structure for mounting photovoltaic modules are:

- Overall dimensions:

$>$ length - $1245 \mathrm{~mm}$;

$>$ width $-635 \mathrm{~mm}$;

$>$ thickness - $7 \mathrm{~mm}$;

$>$ weight $-12 \mathrm{~kg}$.

- Construction to allow easy installation and maintenance;

- Convenient and easy connection of measuring instruments;

- Ergonomically designed and meeting the conditions for safe work and system;

- Resistance to snow and wind loads;

- Corrosion resistance;

The modules are from Solarpro Holding AD [18].

The construction consists of two stands connected to each other by a pipe to which the panel frame is welded. The schematic diagram of the respective structure and its overall dimensions are shown in Fig.1.
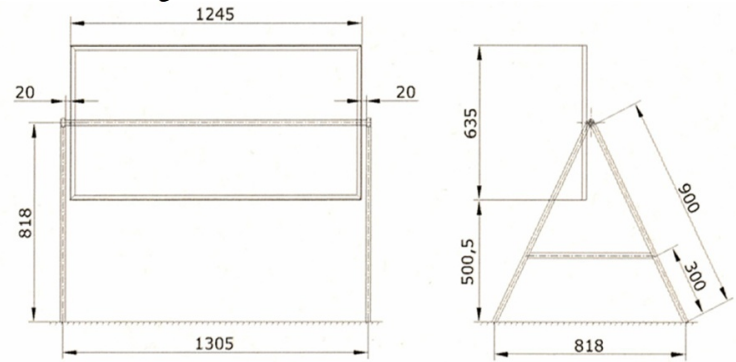

Fig. 1. Schematic diagram of the structure.

The structural elements used for the construction of this structure are shown in Fig. 2. . A square tube with a cross section of $20 \times 20 \times 2 \mathrm{~mm}$ was used for the stands (Fig. 2,1). The solar panel with dimensions is attached to a frame made of L-shaped profiles with a cross section of $20 \times 20 \times 3 \mathrm{~mm}$ (Fig. 2,2). The frame is reinforced in the middle by a pipe with a diameter $\Phi 21,3 \mathrm{~mm}$ (Fig. 2,3), mounted at both ends to the stand.

\subsection{Mechanical load on the structure}


The predominant force acting on the supporting structure of the solar panel is wind. It is determined in accordance with Ordinance № 3 of 21 July 2004 on the basic provisions for the design of construction structures and the impacts on them [19]. The load from the own weight of the structure and the panel is not taken into account, as it is negligible compared to the wind load.
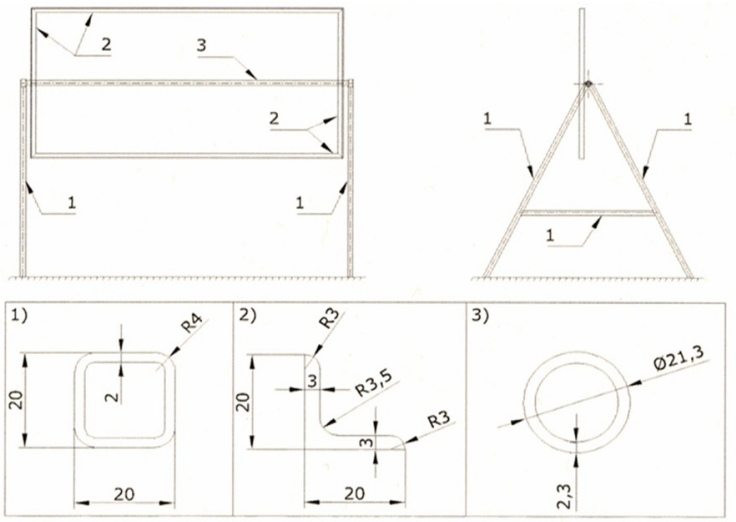

Fig. 2. Structural elements.

According to the Ordinance, the wind load on buildings and facilities is defined as the sum of its average (so-called static) and pulsation component. The normative value of the static component of the wind load $W_{n}$, в $\mathrm{kN} / \mathrm{m}^{2}$ at height $z$ above the terrain is calculated by the formula:

$$
W_{n}=W_{m} \cdot k_{z} \cdot c \cdot \gamma_{f},
$$

where $W_{m}$ is the normative value of the pressure (speed) of the wind. For the region of Ruse $W_{m}=0.5 \mathrm{kN} / \mathrm{m}^{2}$;

$k_{z}$ - the coefficient by which the change in pressure in height is taken into account. The value of the coefficient for buildings up to $10 \mathrm{~m}$ e 1 ;

$c$ - the aerodynamic coefficient. For free-standing flat solid wall constructions $c=$ 0.8 ;

$\gamma_{f}$ - the private impact factor $\left(\gamma_{f}=1.4\right.$ for wind loads.

After taking into account all the coefficients, the value of the static component of the wind load is obtained:

$$
W_{n}=0,5 \cdot 1 \cdot 0,8 \cdot 1,4=0,56 \mathrm{kN} / \mathrm{m}^{2} .
$$

The normative value of the pulsation component of the wind load $W_{p}$ at height $z$ is determined by:

$$
W_{p}=W_{n} \cdot \zeta \cdot v
$$

where $W_{n}$ is the static component of the wind load $\left(W_{n}=0,56\right)$;

$\zeta$ - the coefficient for pulsation of the wind pressure at height $z$. It assumes a value of 0.76 for buildings up to $10 \mathrm{~m}$ high;

$\mathrm{v}$ - coefficient for spatial correlation of wind pressure pulsations, $\mathrm{v}=0,89$.

After taking into account all the coefficients, for the value the component of the wind load is obtained:

and for the total wind load:

$$
W_{p}=0,56.0,76.0,89=0,38, \mathrm{kN} / \mathrm{m}^{2},
$$

$$
W=W_{n}+W_{p}=0,56+0,38=0,94 \mathrm{kN} / \mathrm{m}^{2} .
$$

When performing computer simulations, the wind load is rounded to $1 \mathrm{kN} / \mathrm{m}^{2}$. 


\subsection{Stimulation investigation}

Seven different operating positions of the photovoltaic panel during its rotation from $0^{\circ}$ to $90^{\circ}$ are considered. In each of these positions, a distributed load $q$ with an intensity of 1 $\mathrm{kN} / \mathrm{m}^{2}$. is normally applied to the surface of the panel. The positions for which a strength check of the model has been performed are shown in Fig. 3. To fasten the model, a clamp is accepted at the lower end of the stands.
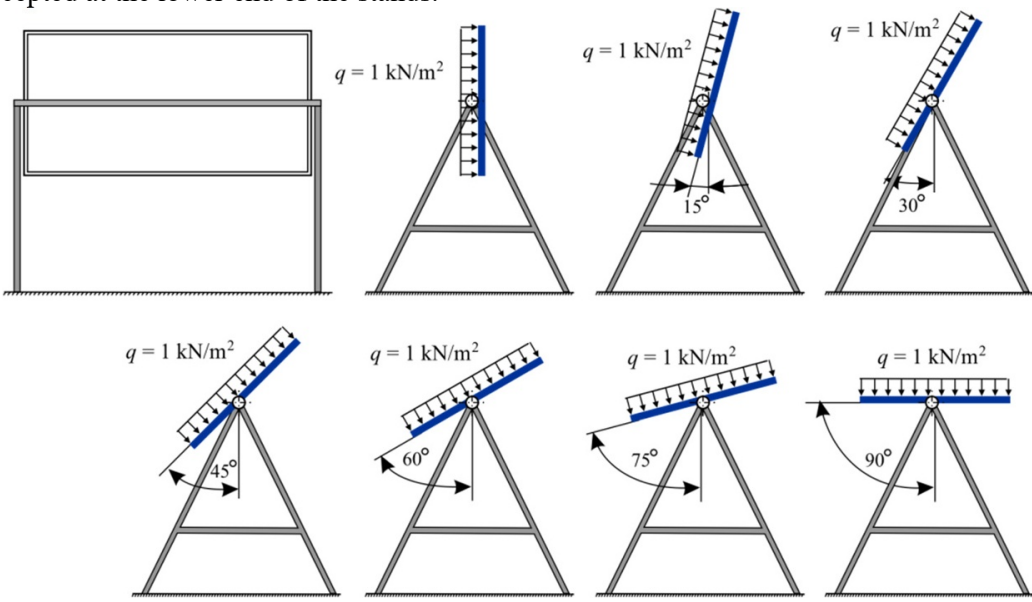

Fig. 3. Diagram of the seven operating positions of the photovoltaic panel

The geometric model shown in Fig. 1, is built of profiles (Fig. 2) and a surface recreating the solar panel. Steel ВСтЗкп was chosen for the profiles (Table. 1.).

Table 1. Technical characteristics of used steel.

\begin{tabular}{|l|c|c|c|}
\hline Features & Designation & Units & Value \\
\hline Density & $\mathrm{P}$ & $\mathrm{kg} / \mathrm{cm}^{3}$ & 7850 \\
\hline Modulus of elasticity & $\mathrm{E}$ & $\mathrm{MPa}$ & $2,06.10^{5}$ \\
\hline Poisson's ratio & $\mathrm{P}$ & - & 0,3 \\
\hline Angular deformation modulus & $\mathrm{G}$ & $\mathrm{MPa}$ & $0,79.10^{5}$ \\
\hline Normative resistance of tensile strength & $\mathrm{Run}$ & $\mathrm{MPa}$ & 370 \\
\hline $\begin{array}{l}\text { Calculated tensile, compressive and bending resistance } \\
\text { from Run }\end{array}$ & $\mathrm{Ru}$ & $\mathrm{MPa}$ & 335 \\
\hline $\begin{array}{l}\text { Normative resistance to tension, pressure and bending } \\
\text { from the city of traction }\end{array}$ & $\mathrm{Ryn}$ & $\mathrm{MPa}$ & 225 \\
\hline $\begin{array}{l}\text { Calculated tensile, compressive and bending resistance } \\
\text { from Ryn }\end{array}$ & $\mathrm{Ry}$ & $\mathrm{MPa}$ & 205 \\
\hline
\end{tabular}

The stimulation task is solved using the finite element method (FEM). For this purpose, a three-dimensional model was built in the SolidWorks program (Fig. 4), which was subsequently analyzed using the COSMOSWorks application. The SolidWorks Office Premium package is used to solve the task [15]. 


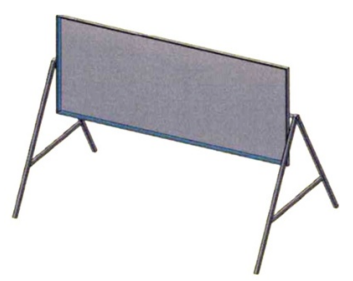

Fig. 4. Three-dimensional model of the experimental circuit with the photovoltaic module

For the surface representing the glass panel, standard material from the COSMOS Works library built into the program was used. It has a modulus of elasticity $E=6,89 \cdot 10^{4} \mathrm{MPa}$ and a Poisson's ratio $\mu=0,23$. The aim of the task is to study the loadbearing capacity of the structure. The surface of the photovoltaic panel is created in the model to transmit the load on the frame. In this regard, the strength of the protective surface glass of the panel is not considered. In solving the problem, it is assumed that all components of the structure are fixedly connected to each other. The whole structure is fixed by tightening the lower ends of the stands (Fig. 5). A wind load is applied to the model, applied to the surface of the panel as a distributed load with an intensity of $1 \mathrm{kN} / \mathrm{m}^{2}$. In Fig. 5. the applied load and the fastening of the model are shown. The places where the structure will be attached to pre-cast concrete "steps" in the ground are shown with a fixed clamp. The metal rods will be attached to them with anchor bolts, three per step, with dimensions. This will ensure that the structure does not react to lifting forces. Wind forces will act on the panels. Since they will be located at a not very high height from the ground, the lifting forces will not be so great. There will be no large side load. Only wind blowing against the panels would create pressure on the entire structure.

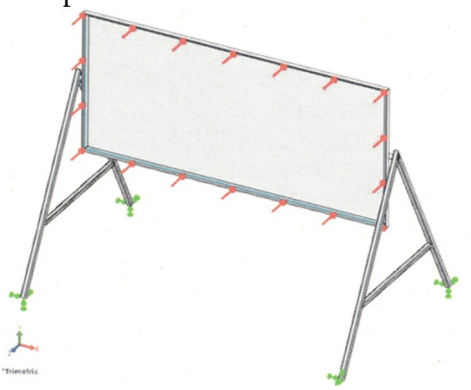

Fig. 5. Applied load and attachment of the model.

The network of finite elements needed to solve the task is created automatically by the COSMOSWorks program after the type of elements and their size are selected. A mixed network of beam and shell finite elements has been created. In this case, two-node beam end elements were used to represent the beams. Each two-node beam element has six degrees of freedom in each node: three translations and three rotations. At the discretization of the glass surface, triangular shell elements of the second row were used. Each triangular element in the second row has six knots: three knots in its vertices and three knots in the middle of its sides. When solving the problem, the nominal size of the element is set to 20 $\mathrm{mm}$. The resulting network of finite elements is shown in Fig. 6. 


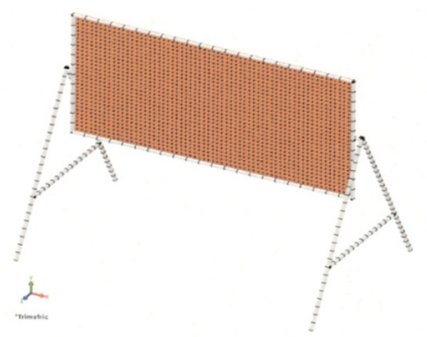

Fig. 6. Created network of finite elements.

The calculations are done for one panel.

It is obvious that when expressing the cutting forces, the triangular part of the structure, as well as the base, is loaded with pressure (Fig. 7.).

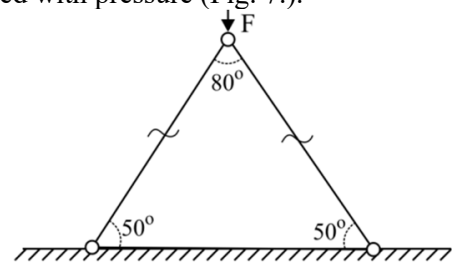

Fig. 7. Pressure load.

The force with which the structure is loaded is:

- $\quad$ force from the weight of the panel $F 1=m \cdot g=17.9,81 \approx 167 \mathrm{~N}$;

- $\quad$ force generated by the wind $F 2=140 . S . g=140.1,27.9,81 \approx 1750 \mathrm{~N}$;

- $\quad$ total strength $F=F 1+F 2=1917 \mathrm{~N}$.

A $x-y$ coordinate system is introduced, according to which the normal cutting forces will be decomposed (Fig. 8.)

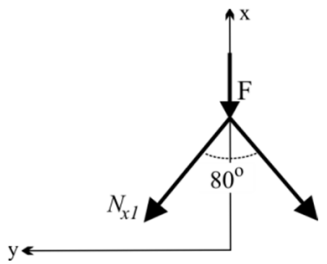

Fig. 8. Shear forces.

The following equations are solved to calculate the stresses in the structure:

$$
\begin{aligned}
& \sum x_{i}=0 ; \sum y_{i}=0 ; \\
& N_{x_{1}} \sin 40^{\circ}-N_{x_{2}} \sin 40^{\circ}=0, \Longrightarrow N_{x_{1}}=N_{x_{2}} ; \\
& -N_{x_{1}} \sin 40^{\circ}-N_{x_{2}} \sin 40^{\circ}-F=0, \Longrightarrow N_{x_{1}} \approx 1438 \mathrm{~N} .
\end{aligned}
$$

The normal shear force has a negative sign, which indicates that the structure is under pressure.

In the cross-section of the structure acting only normal voltages $\sigma_{x}$, which are evenly spaced and have a value:

$$
\sigma_{x}=\frac{N_{x}}{S}=\frac{1438}{0,231} \approx 6225 \mathrm{~Pa} .
$$

Checking the stresses in the bars (square tubes) at the allowable stress $[\sigma]$ is performed using the strength condition: 


$$
[\sigma]=\frac{\sigma_{S}}{n}=\frac{240}{3}=80 \mathrm{MPa}
$$

where $\sigma_{s}$ is the allowable stress for the material is equal to $240 \mathrm{MPa}$;

$n$ - the coefficient of security. The selected value is 3 .

The condition is $\sigma_{x}<[\sigma]$, or $6225<80.10^{6} \mathrm{~Pa}$.

The large difference in allowable stresses indicates that the structure will withstand compressive forces much greater than anticipated.

Determination of support reactions (Fig. 9).

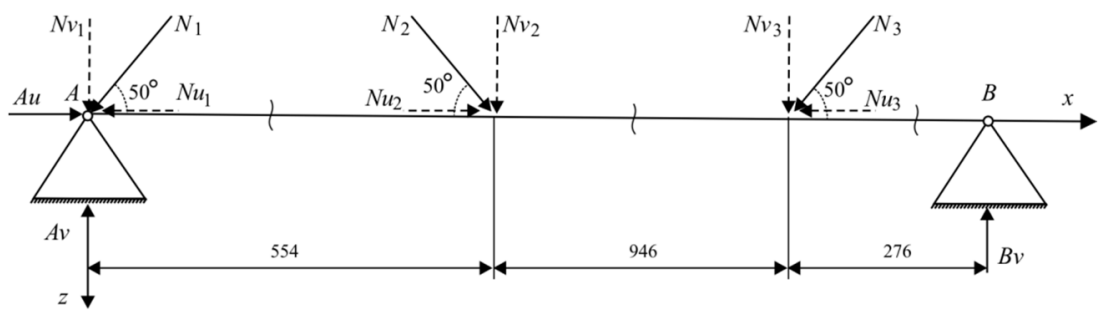

Fig. 9. Support reactions of the experimental model

To find the reference reactions $\mathrm{Au}, \mathrm{Av}$ and $\mathrm{Bv}$ respectively on the entered $x-z$, coordinate axes, the following equations are solved:

$$
\begin{aligned}
& \sum x_{i}=0 ; \\
& A u-N u_{1}+N u_{2}-N u_{3}=0 ; \\
& A u-N_{1} \cdot \cos 50^{\circ}+N_{2} \cdot \cos 50^{\circ}-N_{3} \cdot \cos 50^{\circ}=0 ; \\
& A u=N_{3} \cdot \cos 50^{\circ} \approx 925 \mathrm{~N} . \\
& \sum M_{B i}=0 ; \\
& -1,8 \cdot A v+1,8 \cdot N v_{1}+1,2 \cdot N v_{2}+0,28 \cdot N v_{3}=0 ; \\
& -1,8 \cdot A v+1,8 \cdot \cos 40^{\circ} N_{1}+1,2 \cdot \cos 40^{\circ} N_{2}+0,28 \cdot \cos 40^{\circ} N_{3}=0 ; \\
& A v \approx 3478 \mathrm{~N} . \\
& \sum M_{A i}=0 ; \\
& 1,8 \cdot B v-1,5 \cdot N v_{3}-0,554 \cdot N v_{2}=0 ; \\
& 1,8 \cdot B v+1,5 \cdot \cos 40^{\circ} N_{3}+0,554 \cdot \cos 40^{\circ} N_{2}=0 ; \\
& B v \approx 1258 \mathrm{~N} .
\end{aligned}
$$

The diagrams of the cutting forces are constructed on axes parallel to the geometric axis of the beam (Fig. 10.). It is clear from the diagram that there are no strong jumps in the concentrated forces and moments.

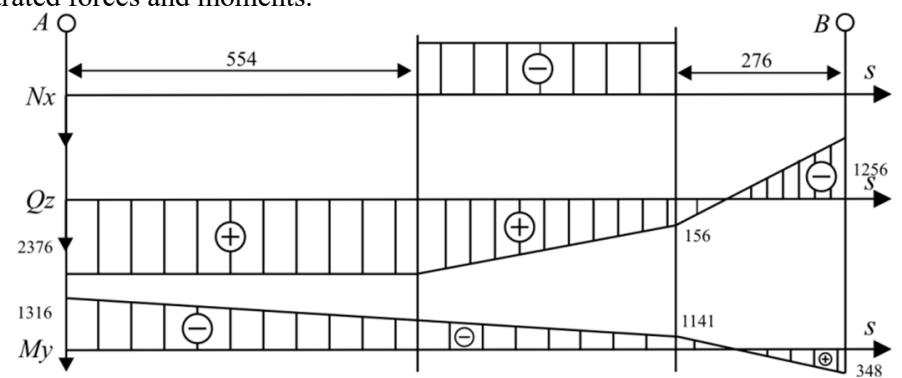

Fig. 10. Diagram of shear forces 
The inclination of the photovoltaic panel is done by a lever mechanism driven by an electric motor for a satellite dish. The maximum angle of rotation of the panels is from $0^{\circ}$ to $90^{\circ}$. The main parameters of the drive mechanism are: maximum stroke: $53 \mathrm{~cm}$; static load: $450 \mathrm{~kg}$; dynamic load: $250 \mathrm{~kg}$; speed of movement: $5.6 \mathrm{~mm} / \mathrm{s}$; supply voltage: $36 \mathrm{~V}$ (Fig. 11).

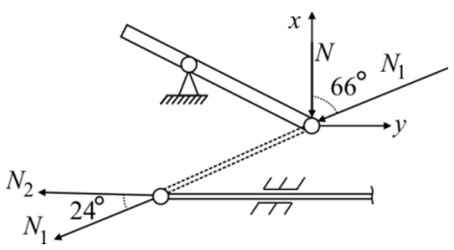

Fig. 11. Kinematic diagram for determining the loads on the drive motor.

We know that the force of gravity of the panel ( $N$ in the figure) amounts to $167 \mathrm{~N}$. To find the force $N_{1}$, at an inclination in the rendered direction, the following equation is solved:

$$
N_{1}=\frac{N}{\cos 66^{\circ}}=\frac{167}{0,407}=410 \mathrm{~N} .
$$

It can be seen that the force $N_{1}$ is transmitted to the lower part of the structure by means of the lever. Again, by solving equation, we find the force $N_{2}$, which acts directly on the engine:

$$
N_{2}=N_{1} \cos 24^{\circ}=374 \mathrm{~N}=37 \mathrm{~kg} \text {. }
$$

Therefore, under both static and dynamic loads, the motor will withstand the load.

\section{Results and Discussion}

Finite element strength (FEM) strength analysis was also performed for seven operating positions of the solar panel (from $0^{\circ}$ to $90^{\circ}$ with a step of $15^{\circ}$ ). The results obtained for each of the cases are presented in graphical form in Fig. 12.

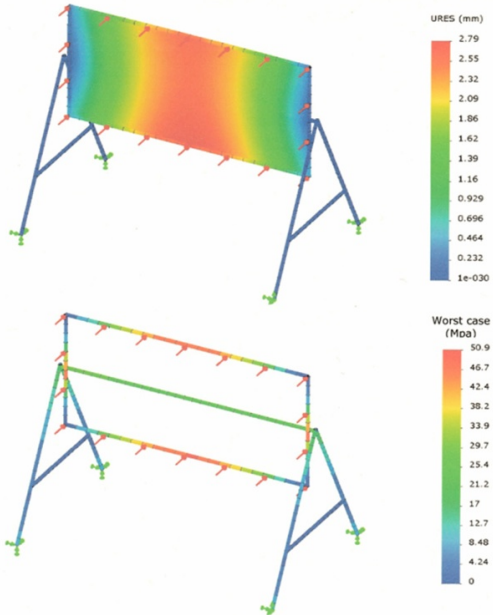

slope panel $0^{\circ}$
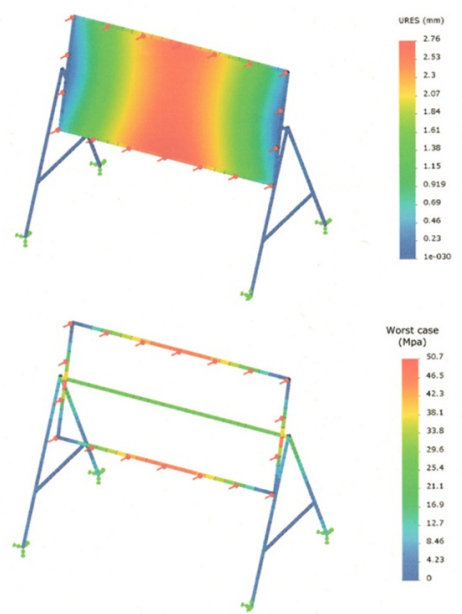

slope panel $15^{\circ}$ 

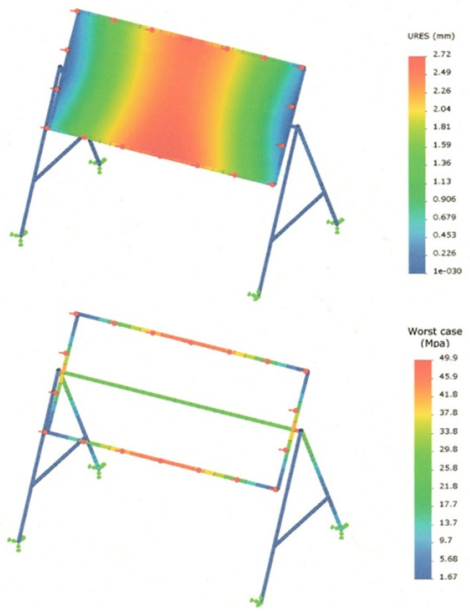

slope panel $30^{\circ}$
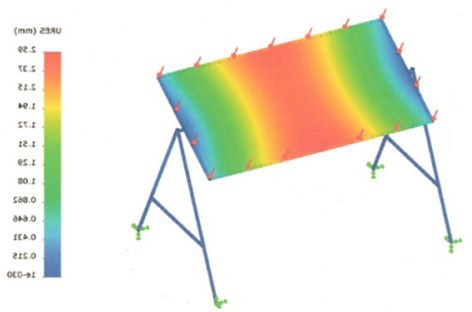

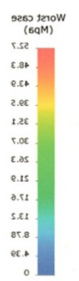

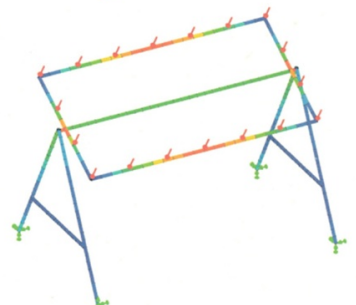

slope panel $60^{\circ}$
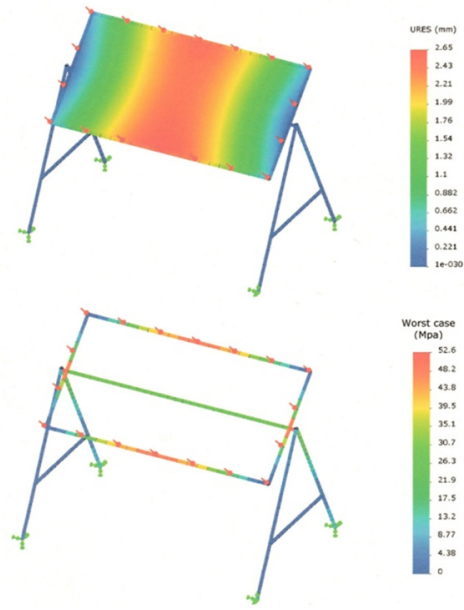

slope panel 45
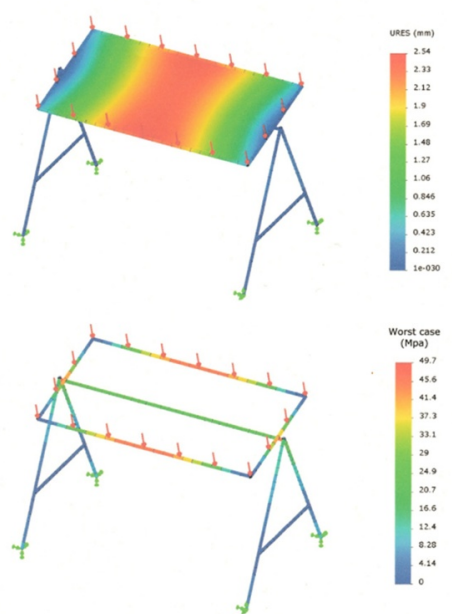

slope panel $75^{\circ}$ 

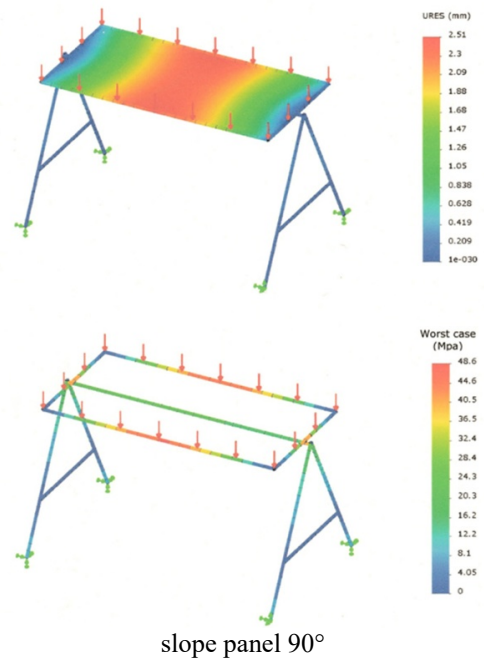

Fig. 12. Displacements and maximum stresses in the beams at different slopes of panel.

The results obtained for each of the cases are presented in graphical form in Figure 12. It is clear from them that for all operating positions of the panel, the maximum stresses are obtained in its frame. These stresses in different cases vary around the value of $50 \mathrm{MPa}$ and are not dangerous for the structure. The maximum stresses for each of the considered cases are presented in a Table 2 .

Table 2. Maximum stresses obtained for operating positions from $0^{\circ}$ to $90^{\circ}$

\begin{tabular}{|c|c|c|c|c|c|c|c|}
\hline Working position & $0^{\circ}$ & $15^{\circ}$ & $30^{\circ}$ & $45^{\circ}$ & $60^{\circ}$ & $75^{\circ}$ & $90^{\circ}$ \\
\hline Maximum mechanical stress (MPa) & 50,9 & 50,7 & 49,9 & 52,6 & 52,7 & 49,7 & 48,6 \\
\hline
\end{tabular}

The analysis of the obtained results shows that the greatest load is in the middle area of the photovoltaic panel. It has a maximum at a perpendicular position of the panel relative to the wind direction, which corresponds to a sloping panel $0^{\circ}$. This load leads to an URES of $2.79 \mathrm{~mm}$, which shows how much the photovoltaic module deforms under the influence of wind force. The least wind load on photovoltaic panels is shown when they are successfully oriented on the earth's surface. This corresponds to a $90^{\circ}$ inclined panel.

\section{Conclusions}

It has been established that the load-bearing structure and the photovoltaic panel must be able to withstand mechanical loads both from their own weight and from snow and wind. The obtained results for the conditions of the city of Ruse, Bulgaria show that for all working positions of the panel the maximum stresses are obtained within its framework. These voltages in different cases vary around the value of $50 \mathrm{MPa}$ and are not dangerous for both the structure and the photovoltaic panel. The greatest load on the panel and the frame is observed in the middle part, with the maximum being at a perpendicular position of the panel with respect to the wind direction, which corresponds to an inclined panel of 0 ${ }^{\circ}$, and the least of an inclined panel of $90^{\circ}$. 


\section{References}

1. Republic of Bulgaria. Ministry of Energy. Ministry of the Environment and Water. Integrated energy and climate plan of the republic of Bulgaria 2021-2030. (2020) https://ec.europa.eu/energy/sites/default/files/documents/bg_final_necp_main_en.pdf

2. T. Pavlovic, P.T. Tsankov, N.D. Cekić, I.S. Radonjić Mitić, Photovoltaic solar energy conversion, The Sun and Photovoltaic Technologies (2020) DOI: 10.1007/978-3-03022403-5

3. I. Stoyanov, T. Iliev, An integrated approach for improvement of the efficiency of the photovoltaic system by using cogeneration, Bulgarian Chemical Communications, Volume 52, Special Issue C, pp. 46-52, (2020) DOI: 10.34049/bcc.52.C.0102.

4. M. Mehmed-Hamza and P. Stanchev, Overcurrent Protection Against Faults in Smart Grids, 11th Electrical Engineering Faculty Conference BulEF (2019), pp. 1-4, DOI: 10.1109/BulEF48056.2019.9030744

5. Zlatov, N., Iliev, I., Terziev, A., Kamburova, V., Estimation of the photovoltaic modules energy production in respect of the PV inclination angle (2014) art. no. 6920446, DOI: 10.1109/REM.2014.6920446

6. P. Hristov, T. Hristova, Explaining The DLT Applications in The Context of a Customers, Facility Managements and Utility Companies Relationship, 16th Conference on Electrical Machines, Drives and Power Systems ELMA (2019), pp. 1-5, DOI: 10.1109/ELMA.2019.8771693

7. M. Pandursi, F. Tsvetanov, Journal of Engineering Science and Technology Review SI, pp. 32-36 (2020)

8. C. Osterwald, T. McMahom, History of Accelerated and Qualification Testing of Terrestrial Photovoltaic Modules: A Literature Review. Prog. Photovolt: Res. Appl., 11-33 (2009)

9. O. Al-Habahbeh, B. Al-Hrout, E. Al-Hiary, S. Al-Fraihat, Reliability Investigation of Photovoltaic Cell Using Finite Element Modeling, Proceedings of 9tn International Symposium on Mechatronics and its Applications (2013)

10. M. Kempe, D. Holsapple, K. Whitfield, N. Shiradkar, Standards development for modules in high temperature micro-environments, Progress in Photovoltaics: Research and Applications, 10.1002/pip.3389, 29, 4, pp. 445-460 (2021)

11. P. Zlateva, L. Yordanov, R. Petkova-Slipets, A study of the thermal properties of an alternative straw-containing building material. E3S Web Conf., 207 (2020) 01004, https://doi.org/10.1051/e3sconf/202020701004

12. A. Terziev, Analysis of the terrain specifics and roughness factor on the wind shear over complex terrains, (2019) 595 (1), art. no. 012043, DOI: 10.1088/1757899X/595/1/012043, ISSN: 17578981

13. I. Stoyanov, T. Iliev, G. Mihaylov and E. Ivanova, Synthesis and design of virtual measurement system for investigation on photovoltaic modules, 10th International Symposium on Advanced Topics in Electrical Engineering ATEE (2017), pp. 915-918, doi: 10.1109/ATEE.2017.7905070.

14. A. Sinha, D. B Sulas-Kern, M. Owen-Bellini, L. Spinella, S. Uličná, S. Pelaez, S. Johnston, L. T Schelhas, Glass/glass photovoltaic module reliability and degradation: a review, Journal of Physics D: Applied Physics, 10.1088/1361-6463/ac1462, 54, 41, $413002(2021)$

15. M. Owen-Bellini, P. Hacke, D. C. Miller, M. D. Kempe, S. Spataru, T. Tanahashi, S. Mitterhofer, M. Jankovec, M. Topič, Advancing reliability assessments of photovoltaic 
modules and materials using combined-accelerated stress testing, Progress in Photovoltaics: Research and Applications, 10.1002/pip.3342, 29, 1, pp. 64-82, (2020)

16. J. H. Wohlgemuth, Development of Accelerated Stress Tests, Photovoltaic Module Reliability, 10.1002/9781119459019, pp. 55-65, (2020)

17. J. Fonseca, F. Oliveira, C. Prieb, A. Krenzinger, Degradation analysis of a photovoltaic generator after operating for 15 years in southern Brazil, Solar Energy, 10.1016/j.solener.2019.11.086, 196, 196-206 (2020)

18. https://solarpro.bg/

19. Ordinance № 3 of 21 July 2004 on the basic provisions for the design of construction structures and the impacts on them (in Bulgarian). Source: https://www.mrrb.bg/bg/naredba-3-ot-21-yuli-2004-g-za-osnovnite-polojeniya-zaproektirane-na-konstrukciite-na-stroejite-i-za-vuzdejstviyata-vurhu-tyah/ 